\title{
Developing an Asynchronous Course Model at a Large, Urban University
}

\author{
Anthony G. Picciano \\ Professor, Division of Programs in Education, Department of Curriculum and Teaching, \\ Hunter College of the City University of New York, \\ 695 Park Avenue, New York, NY 10021 \\ e-mail : antho13926@aol.com
}

\begin{abstract}
In Spring 1997, Hunter College offered the first asynchronous learning course in the City University of New York (CUNY), the largest urban university system in the United States enrolling 200,000 students in undergraduate and graduate programs. This graduate course, entitled Administration and Supervision of the Public Schools - The Principalship, was offered in the Division of Programs in Education. Funded by the Alfred P. Sloan Foundation, this course was intended to serve as a model for other courses at Hunter College and CUNY.

While many colleges have begun to offer asynchronous learning courses, the model presented here may be of special interest since it takes into consideration several variables of importance in large urban environments. First, all of the students in this course were adult, part-time students who delicately balance studies, careers, and families in their daily lives. In this respect, they represented a typical urban commuter population that would benefit from the convenience of asynchronous learning. Second, all of the students were commuter students who participated in the course via equipment located in their homes and offices. As a result, the model had to accept a wide variety of on-line services as the means of participation. Third, these students did not possess extensive technical skills and in terms of expertise could be classified as new to intermediate. This required that the model employ simple software interfaces that would minimize student frustration due to technical difficulties. Lastly, all of these students already had earned masters degrees and were teachers in the New York City metropolitan area. As experienced teachers, they are attuned to pedagogy and could provide valuable insight into an evaluation of the instructional components of the model.
\end{abstract}

The purpose of this paper is to share the results of a student evaluation of the instructional components of an asynchronous model that might be beneficial to others who are considering using this technology in similar environments.

\section{Keywords}

Asynchronous learning

Computer-mediated learning

Computer-mediated instruction

Computer-mediated communications

Distance learning

Education administration 


\section{INTRODUCTION}

On April 9, 1997, educators from twenty-two countries met in Salzburg, Austria to attend a nineday seminar on distance learning. The focus of the seminar was to share experiences in planning and implementing distance learning projects for teaching English as a foreign language in their countries. In Iceland, radio transmission is used to provide instruction to fishermen who spend weeks at sea. In Indonesia, television is used to provide basic language literacy to inhabitants of the hundreds of islands that make up this country. In India and Pakistan, a combination of mail, television, and the Internet is being considered to improve English language skills in villages in the remote northern mountain provinces. When considering distance learning, images of great distances or geographic obstacles are frequently invoked to provide a basic rationale for why alternate forms of instruction are required. However, this may not always be the case.

Students who lead busy lives in large metropolitan areas such as New York City are showing an interest in taking distance learning courses in their homes or places of business because of the increasing time demands of their families or jobs. At City University of New York (CUNY), the largest urban university in the United States, with more than 200,000 students in twenty colleges within the confines of 321 square miles, the first asynchronous learning course using the Internet was conducted at Hunter College in Spring 1997. This graduate course, entitled Administration and Supervision of the Public Schools - The Principalship, was offered in the Division of Programs in Education. Funded by the Alfred P. Sloan Foundation, it was intended to serve as a model for other courses at Hunter College and CUNY. If successful, it was anticipated that faculty and students in other CUNY colleges would consider taking advantage of this type of learning. The purpose of this study was to examine student learning experiences particularly with regard to issues of instructional design as applied to the asynchronous learning model used in this course at Hunter College.

Asynchronous learning has been used in various forms throughout the world for decades. The United Kingdom's Open University serves as one of the more successful models of this type of learning. However, the term asynchronous learning has been made popular in the United States in recent years because of the major funding provided by the Sloan Foundation program for asynchronous learning networks (ALN). It is related to the terms, computer-mediated learning, computer-mediated instruction, and computer-mediated communications, in which the computer is used as a tool for supporting instructional activities. For purposes of this study, asynchronous learning is defined as learning at anytime or in anyplace using Internet and World Wide Web software tools (e-mail, electronic bulletin boards, and Web pages) as the main vehicles for instruction.

\section{REVIEW OF THE LITERATURE}

It is not the intent here to undertake an extensive review of the literature on distance learning. Excellent reviews have been provided in recent years by Schlosser and Anderson [1], Moore and Kearsley [2], and Sherry [3], However, a brief look at some of the current literature on asynchronous learning would be helpful for framing the subject of this study. More specifically, since the focus of this study was student learning experiences and issues of instructional design, research related to this aspect of asynchronous learning was reviewed. 
A fundamental aspect of learning is the social and communicative interactions between student and teacher, and student and student. This is true in face-to-face as well as asynchronous learning activities [4]. The ability to ask a question, to share an opinion with a fellow student, or to disagree with the point of view in a reading assignment is critical to student learning. Several aspects of asynchronous learning require adjustments on the part of students and teachers for successful interactions to occur.

Ruberg, Taylor, and Moore [5] observed that students must adjust to the non-linear nature of asynchronous learning that is not typical in face-to-face situations which tend to be linear focusing on a single discussion thread. Asynchronous learning sessions can have multiple threads with several discussions and interactions progressing. Students can be responding to the teacher but also to other students depending on their interest and point of view. Students can initiate a new discussion as easily as the teacher. In this respect, asynchronous learning can empower students and allow them to participate on an equal basis with the teacher in establishing and pursuing discussion topics.

With this empowerment comes responsibility and an important aspect of a successful asynchronous learning activity is whether or not students adjust to this new role [6]. Teachers find they have to allow students to exercise and develop this responsibility. A teacher becomes a facilitator of instruction and assists students in pursuing threads within a discussion that the students determine are important. Lippman [7] and Anderson [8] refer to this as creating a "community of inquiry" wherein all participants are equal and able to initiate or pursue topics as they wish.

Developing this community of inquiry is not without potential problems. Students in this environment need to understand their responsibility for being active contributors to instruction. They cannot assume that others, either teachers or students, will simply carry the instructional load. This favors a more mature student who is self-directed and willing to take on responsibility for learning. To a degree, this supports findings that mature, motivated students are typically better suited for asynchronous and distance learning activities [2].

In addition to accepting responsibility, students also need to have the experience and knowledge base to sift the discussion for misinformation. Sproull and Kiesler [9] caution about discussions that continue based on misinformation because in asynchronous mode an instructor cannot immediately correct or clarify a comment. This may be dismissed as not a serious issue but with the amount of information being provided, this can be more troublesome than it appears. In asynchronous learning, the amount of student participation can increase and the number of comments can easily lead to what Mackay [10] described as information overload. Furthermore, comments in on-line discussions tend to be longer than in face-to-face situations. With more information from many sources, students need to be more attentive to both the who and what of a discussion. Herbert Simon, economist and Nobel Prize laureate, succinctly cautions that "a wealth of information can create a poverty of attention," ([11], p. 200).

Another aspect of interaction and communication that can be problematic in an asynchronous environment is the loss of visual clues during a discussion. Body language is important in a faceto-face classroom discussion. A smile on a student's face is interpreted by the teacher as a sign of understanding; a student nervously looking at his wristwatch is interpreted as boredom or lack of patience. On the other hand, a teacher motivates or provides emphasis with inflection or hand movement. However, Sproull and Kiesler [9] point out that while these visual signs may be helpful, 
if misinterpreted, they may also be detrimental. Regardless, they exist and duplicating visual clues in an on-line discussion is not that simple. Other clues may be identifiable by closely reading wording or the turn of a phrase in an e-mail message or posting.

Technical issues associated with student participation in asynchronous discussions cannot be minimized particularly if access takes place in homes or in places of business. It is difficult to control these environments and the students again must assume a certain responsibility for assuring their access to technology. Teachers likewise need to become familiar with the technology so as to be able to use it routinely but also to assist students having technical problems. Sherry [3] emphasizes that instructional needs of students and not the technology must be the focus of learning. Situations wherein students or teachers are having technical difficulties distract from the major learning objectives. On the other hand, technology may initially be perceived as chic with a bit of wonder. Students willingly participate because of the novelty or "fun" of using technology. Trentin [12] observed that network-based learning can quickly fall into a "rut" if activities are not well-organized and structured to last for the duration of the learning cycle or period. Wellpresented content in the final analysis is as important as the technology.

In summary, a good deal of research has been conducted on distance learning. However, as technology advances and changes, so do the issues associated with the design of instructional models. While researchers can draw from the past for insight, new situations using new technology require continual study and evaluation. As the Internet and other network-based technologies advance, opportunities arise for developing new approaches to instruction such as asynchronous learning networks. As educators attempt to develop and implement these approaches, on-going evaluation and study particularly from the student perspective will be necessary.

\section{METHODOLOGY}

\section{A. The Course - ADSUP 702}

The Education Administration and Supervision Program at Hunter College is a thirty-credit graduate program leading to New York State certification as a school administrator. New York State requires a minimum of eighteen graduate credits plus an internship. The program at Hunter requires twenty-four credits (eight courses) plus six credits for an internship.

The course offered in an asynchronous learning mode entitled, Administration and Supervision (ADSUP) 702 - Organization and Administration of the Public Schools - The Principalship, is a required course. This course is designed as an introduction to the issues of school organization and administration. These include leadership, school finance, curriculum, and dealing with various building-level constituents. The course examines the principal as both the instructional and administrative leader in the teaching/learning environment. It was considered to be appropriate for asynchronous delivery because it requires a good deal of self-directed reading and study on the part of students as is appropriate for advanced graduate studies. Faculty teaching this course guide students as they pursue topics as well as formally teach subject matter.

\section{B. The Students}

To enroll in the graduate program in Education Administration and Supervision at Hunter College, all students must have at least five years of teaching experience and earned masters degrees. More 
than $80 \%$ are women. Approximately $25 \%$ are students from minority groupings. Almost all of them pay their own tuition which for some is a financial burden. Some students have made the decision to attend classes rather than take on a second job as coaches, tutors, or other after-school positions. Approximately $80 \%$ percent of these students work in New York City public schools while the remaining $20 \%$ work in private schools or in public schools outside of New York City. For the past ten years, the program has maintained an enrollment of 100 to 125 students, almost all of whom are part-time. Because of funding and a desire to insure academic quality, the enrollment in the program has been limited.

All of the students are education professionals already certified as teachers by New York State. They are dedicated to their profession and are expending enormous energy in improving their skills and abilities in order to become school administrators (principals, assistant principals, directors of programs). New York State, like most states, requires a graduate program for individuals to become certified as school administrators. These students represent a group of self-starters who are conscientious and view their studies as vehicles for professional growth and advancement. They recognize the importance of technology and approximately $40 \%$ of the program's enrollees have access to computer and Internet technology either in their homes or in their schools. Many of these students are professionally curious about an alternative pedagogical experience such as asynchronous learning using the Internet and other current technological tools.

All of the students are commuters who balance full-time jobs, families, parenthood, and higher education in a carefully planned day which includes rushing for subways and buses to meet the next commitment. They are a mature group who organize their daily lives around lesson plans, making sure their children get to the baby sitter or day care center, maintaining a home, and when time permits, completing home work assignments. Offering a course to them that can be taken at anytime or in anyplace would surely have a good deal of appeal. They would be able to fit their graduate studies into their busy lives and eliminate the need to travel several times per week to the College. For the purposes of experimenting with a distance learning model, these students typify the mature, self-directed, and busy "students" who could take advantage of and benefit from this form of instruction.

From the group described above, seventeen $(\mathrm{N}=17)$ students enrolled in ADSUP 702 for Spring 1997. Their average age was thirty-six years. Thirteen were female and four were male. The ethnic composition was as follows: two were African-American; two were Latino, and thirteen were White/Caucasian. All of these students volunteered to take this course. Thirteen of the students accessed the Internet at home, two had access in their schools, and two had access at home and school.

\section{Instructional Components}

The model for delivering this course asynchronously was designed to utilize the Internet, World Wide Web, LISTSERV, and e-mail facilities. Prior to Spring 1997, the instructor had been using World Wide Web software and e-mail to enhance courses taught in traditional settings. Students had been able to access syllabi, assignments, and lecture notes via Web pages in these courses. Students had also been able to make one-to-one inquiries of the instructor using e-mail. However, actually teaching using any of the above technologies had not been attempted at Hunter College until Spring 1997. To deliver instruction and to provide the basic interactive components, LISTSERV software was used to conduct on-line group discussions. Students used e-mail software 
to connect to a LISTSERV that was set up specifically for the course. The instructor conducting the course was responsible for establishing and administering the LIST.

The course was organized according to themes and weekly topics. The Web site (see URL: http://discovery.hunter.cuny.edu/ tpiccian/ad702297.html) for the course contained twenty-four Web pages that included a syllabus, reading assignments, weekly discussion topics and questions, supplementary reading material, and related links. These materials were always available and served as the organizational anchors for the course. Each topic was organized for discussion on the LISTSERV during a specific week and based on assigned readings and case studies. Four students were selected each week along with the instructor to be the co-discussion leaders. The use of students as co-discussion leaders was designed to encourage them to be contributors to and not simply receivers of learning activities. Once the discussion of a topic commenced on Monday morning, any student could contribute to the discussion, ask a question of another student or the instructor. At the end of a week's discussion, the instructor summarized the topic, added additional notes and comments, and posted these to the Web site for access by the entire class.

To connect to the LISTSERV, students used any commercial or other Internet and e-mail provider such as America On-line, Compuserve, or Prodigy. While utilization of a communications software package such as Lotus Notes was considered, it was determined that it would be too cumbersome to require all the students to acquire and load this software on their computer systems at home or in their schools.

To provide students with a "comfort level" in using asynchronous technology for instruction, monthly evaluation sessions were held in which students met with the instructor as a group. Individual meetings with the instructor were also available during regularly scheduled conference times. While all students participated in the monthly sessions, very few students met privately with the instructor for a conference and instead used e-mail extensively for one-to-one inquiries and discussions with the instructor.

\section{Evaluation Techniques}

As stated earlier, the major purpose of this study was to examine the student learning experiences in taking an asynchronous course. To accomplish this, a combination of quantitative and qualitative data was collected. Students were asked to keep logs of their weekly activities for certain periods which they turned in to the instructor. Students completed satisfaction surveys at the fifth week and again at the end of the course (fourteenth week). At the end of the course, students were also asked to write an evaluation of their experiences with the course addressing specific questions such as:

1. Do you feel that this course was successful for you?

2. Do you feel that your overall learning was less than, about the same, or greater than in a traditional course?

3. If successful, what aspects of the course contributed to its success?

4. If unsuccessful, what aspects of the course proved problematic for you?

5. What suggestions do you have for improving this course?

6. Would you take another asynchronous learning course if offered here at Hunter College? 
7. Would you recommend that other students in the Administration and Supervision Program take an asynchronous learning course?

8. Provide any other comments that you think would be helpful for this evaluation.

No attempt was made to gather specific student performance data for this study. Performance data may be incorporated into a future study Grading for the course was based on writing assignments, class participation especially as discussion leaders, and a term project. Students had the option of submitting their assignments via e-mail or through the regular mail.

\section{RESULTS}

\section{A. Student Participation}

Critical to an instructional activity is the level of participation which was measured by monitoring weekly on-line postings to the LISTSERV. Data was maintained by both students and the instructor during the length (fourteen weeks) of the course. On average, students made 30.66 postings per week on the LISTSERV ranging from 17 to 46 postings per week, or almost two (1.81) postings per student per week. The lowest number of postings (17) occurred during Week 1. The instructor made on average 4.5 postings per week. The number of individual students posting on the LISTSERV averaged 15.08 students per week with a range of 12 to 17 students. This represents an $88.7 \%$ average weekly participation on the part of students. This compares favorably if not exceeds many traditional, face-to-face classes. Students accepted the responsibilities of their roles as active participants in teaching and learning. In discussing their participation, students commented that the technique of using them as co-discussion leaders contributed to their active participation. Students were not only responding to the instructor but also to comments and questions raised by several of their colleagues. This technique worked well and is highly recommended to others considering developing asynchronous learning models.

In addition to the number of postings, students were asked to maintain time-logs for several weeks during the course. These time-logs recorded any course-related on-line activity whether reading a fellow student's posting, entering one's own posting, e-mailing the instructor, or accessing the course's Web site. They were not to reflect time spent doing reading or writing assignments. The traditional face-to-face class time for this course is 100 minutes (2 fifty-minute sessions) plus optional conference time with the instructor. For one sample week, students logged on an average of 5.64 times and averaged 147 minutes of on-line activity with a range of 125 minutes to 180 minutes. This provides an overview of "class" time and indicates that many students were engaged almost daily and for longer periods than would normally occur in a traditional face-to-face course. However, these figures should be interpreted carefully because student efficiency in using LISTSERV and e-mail facilities varied. For example, some students composed e-mail messages and postings while logged on while others composed messages off-line on word processors and than simply "copied and pasted" them while on-line.

Overall, students spent more time directly in "class" in the asynchronous course than they would have in a traditional course. Postings to the LISTSERV were frequently two or three paragraphs and required the students to read carefully their colleagues' comments. Likewise, in developing their own postings, students tended to reflect and think through their comments. In this respect, the 
asynchronous course seemed to provide more opportunity for reflective practice than spontaneous reaction as is typical in a traditional class.

\section{B. Student Satisfaction Survey}

Data on student satisfaction with their learning experiences were measured using a student satisfaction survey administered at the fifth week and at again at the fourteenth week of the semester. The survey, designed specifically for this course, asked a series of questions regarding student experiences in taking this course in comparison to traditional face-to-face courses. The survey was administered twice to determine if there was any change in student satisfaction during the length of the course. In the data provided in Table 1, responses were based on a five-point Likert scale with $1=$ decreased, $2=$ somewhat decreased, $3=$ no change, $4=$ somewhat increased, and $5=$ increased. A sample question was: "In comparison to a traditional class, in this course the quantity (or quality) of interaction decreased -> increased?" The means of the student responses to the items are summarized in Table 1.

\begin{tabular}{|l|l|l|l|}
\hline Survey Item & 5th Week & 14th Week & Total \\
\hline $\begin{array}{l}\text { Amount of interaction } \\
\text { with other students } \\
\text { decreased/increased }\end{array}$ & 4.12 & 4.88 & 4.00 \\
\hline $\begin{array}{l}\text { Quality of interaction } \\
\text { with other students } \\
\text { decreased/increased }\end{array}$ & 4.29 & 4.29 & 4.29 \\
\hline $\begin{array}{l}\text { Amount of interaction } \\
\text { with the instructor } \\
\text { decreased/increased }\end{array}$ & 3.82 & 4.06 & 3.94 \\
\hline $\begin{array}{l}\text { Quality of interaction } \\
\text { with the instructor } \\
\text { decreased/increased }\end{array}$ & 4.06 & 4.41 & 4.23 \\
\hline $\begin{array}{l}\text { Quantity of your } \\
\text { learning experience } \\
\text { decreased/increased }\end{array}$ & $4.06 *$ & $4.64 *$ & 4.35 \\
\hline $\begin{array}{l}\text { Quality of your } \\
\text { learning experience } \\
\text { decreased/increased }\end{array}$ & 4.41 & 4.53 & 4.47 \\
\hline $\begin{array}{l}\text { Motivation in class } \\
\text { participate in } \\
\text { activities decreased/ } \\
\text { increased }\end{array}$ & 4.35 & 4.47 & 4.41 \\
\hline $\begin{array}{l}\text { Overall Experience - } \\
\text { poor/excellent }\end{array}$ & 4.41 & & \\
\hline
\end{tabular}

Mean Responses $(\mathrm{N}=17) *$ Statistically Significant Difference at the .05 Level

Table 1. Student Satisfaction with the Course

The data in Table 1 indicates that a high level of student satisfaction with their learning experiences was present at both intervals (fifth and fourteenth weeks). With the exception of the "quantity of your learning experiences" students were consistent in their responses on all questions. 
The "quantity of your learning experiences" was the only question that had a statistically significant difference in Week 5 compared to Week 14. One interpretation of this difference was that after fourteen weeks, the students were exposed to significantly more material than after five weeks and hence the "quantity of learning experiences" increased.

This was the first time that any of these students had taken an asynchronous course. While all had access to the Internet, they were not necessarily highly experienced computer users. Most of them considered themselves intermediate computer users. In designing the technological components of the course, a significant effort was made to keep them simple and less intrusive into the instructional process and to minimize student frustration with the technology. A series of questions was asked of the students with regard to their experiences with using technology for this course. Responses were based on a four-point scale with $1=$ not a problem, $2=$ minor problem, 3 $=$ moderate problem, and $4=$ major problem. The means of the student responses to these items are summarized in Table 2.

\begin{tabular}{|l|l|l|l|}
\hline Survey Item & 5th Week & 14th Week & Total \\
\hline $\begin{array}{l}\text { My familiarity with technology was } \\
\text { not a problem/major problem }\end{array}$ & 1.18 & 1.18 & 1.18 \\
\hline $\begin{array}{l}\text { Ability to get on-line was not a } \\
\text { problem/major problem because of } \\
\text { time constraints }\end{array}$ & 1.53 & 1.59 & 1.56 \\
\hline $\begin{array}{l}\text { Ability to get on-line was not a } \\
\text { problem/major problem because of } \\
\text { technical difficulties }\end{array}$ & 1.35 & 1.35 & 1.35 \\
\hline $\begin{array}{l}\text { Use of the computer took more time } \\
\text { than it was worth was not a } \\
\text { problem/major problem }\end{array}$ & 1.06 & 1.06 & 1.06 \\
\hline $\begin{array}{l}\text { Using technology in this course was } \\
\text { easy/difficult }\end{array}$ & 1.29 & 1.35 & 1.32 \\
\hline
\end{tabular}

Mean Responses ( $\mathrm{N}=17)$

Table 2. Experiences with the Use of Technology in the Course

The results in Table 2 indicate that the technology in general was easy to use and did not pose any significant problem in allowing students to participate in class activities. In discussing the survey results with the students, the only major comment with regard to using the technology was with the difficulty especially in February and March, of logging on to the America On-Line service. It was during this period that America On-line experienced significant congestion due to oversubscribing its service. Most students, however, quickly learned that logging on at non-peak hours (early morning/late night) enhanced their ability to connect to the service.

\section{Selected Student Evaluation Comments}


Students were asked to write an evaluation of the course and to respond to specific questions enumerated in the methodology above. Generally, the student evaluations were three to five pages in length. Below is a small sample of some of their comments, chosen to provide insights into issues of success and concern in participating in this course. These comments are organized according to themes that were repeated by several students.

\section{Posting to a LISTSERV vs. Speaking up in a Traditional Class}

"I was very hesitant to write my first comment. I guess I felt exposed. Writing a comment allows for more scrutiny. Participating in [a traditional] class is easier. You say a brief comment and it is considered briefly".----Rochelle

"It was interesting to see how everyone interpreted the question, and then responded to each other. In a regular class, many people would not have contributed because they either felt uncomfortable speaking or feared repeating another person's comments."----Todd

"In a [traditional] classroom setting, not everyone is comfortable speaking. In a fast-paced class, individuals who need more time to process information before speaking, may not get the opportunity to be involved in the discussion."----Sonya

\section{Time Commitment to an Asynchronous Course}

"I will never fall behind on discussions again. It was awful trying to catch up on everyone's comments....I find the discussion more in-depth than a traditional course."----Bonnie

"I am enjoying reading the comments of my peers, but it is sometimes overwhelming to read all of the replies"----Lori

"They [asynchronous classes] are good learning opportunities if one is committed to the time it takes."----Joanna

\section{Student/Instructor Roles}

"Seems like we're all becoming more comfortable--much more interchange....Dr. P's comments help center the discussion and move it forward."----Shelley

"Learning is very much alive! I can't wait to see where the discussion is going. There is always time for that extra comment or question. The bell never rings and the class is never over....E-mates are always prepared."----Sonya

"I found it intriguing that I felt like I was in a classroom even though I was in front of a computer."----Paulette

"The system is relatively easy to use. Advice and assistance from the instructor were frequent and effective."----Dan

"It seems we [students] have more of a voice in the discussion."----Rochelle

"It is a totally different way of learning and sharing."----Judy 
"This course requires students to read and prepare in order to participate and respond. It provides a good opportunity for learning."----Lori

"Increased reflection and intelligent discussion on my part and others in class."----Shelley

\section{Convenience of Taking an Asynchronous Course}

"As graduate students, most of us work. It is hard to travel from point A to point

B...Asynchronous classes are a solution to our high-paced, hectic lives."----Rick

"It is a more flexible form of class and allows one to participate around one's personal life."----Devorah

"The fact that I can log on at my convenience and as often as I want...I can work at my own pace."----Mirza

"[While] it reduces travel time, saves money, and people can work in the privacy of their homes, as a full-time working mother and student, it has been difficult to find the time every night to participate. In [a traditional] class, there are not disturbances from members of the family."---Teresa

\section{Interpreting the Selected Student Evaluation Comments}

The student evaluations provided good insight into some of the dynamics of asynchronous learning. It is interesting to note that even with this experienced group of teachers, concern about speaking up in a class exists. The asynchronous learning approach does not remove this aspect of a class but reshapes the concern from speaking up for a moment in a traditional class to opening oneself up to "more scrutiny" by having to write more extensive comments which become available for continual review. The students' evaluation comments indicate that while some students prefer speaking up in class, others do not. On the other hand, some students preferred having the time to develop their thoughts before expressing themselves which is not always possible in a traditional class because the discussion moves on. In designing asynchronous learning models, expanding the time provided for reflective activity is highly desirable. However, a balance in terms of time allocated for discussing a topic and student time commitments should be struck so that the discussion topic does not seem to "go on and on" without closure.

Asynchronous learning in this class took more time than would have been necessary in a traditional class. Reading and writing substantive LISTERV postings took more time than the normal exchanges in a traditional class. To a degree, students had to get used to this type of interaction. At the beginning of the course, their postings tended to be several paragraphs in length. This was the subject of one of the early monthly evaluation sessions, and the point was well made by the students themselves that while not wanting to inhibit anyone from expressing themselves, succinctness in posting LISTSERV messages would be appreciated.

Student and instructor roles were changed in the asynchronous course. The students had more of a voice in the discussions. As mentioned earlier, the students on average made 30.66 postings per week while the instructor made 4.5 postings per week. Clearly, students were reading a good deal more of each other's comments/questions than those of the instructor. In addition, students were able to establish new threads that became the foci of a substantial part of some weeks' discussion. 
The students in this class accepted this empowerment and responsibility. In conducting an asynchronous learning course, instructors should be prepared to share some of their traditional centeredness with the students. However, this does not mean that the instructor take a laissez-faire approach; to the contrary, the instructor may have to be more involved as a facilitator of learning. It will also require additional time for the faculty member to adjust his or her teaching style to asynchronous activities.

A major reason for experimenting with asynchronous learning in a large urban university was to provide a convenience for students. While most students commented that this was indeed the case, ironically some cited distractions and disturbances at home that they would not have had in class at the college. While at home or work, the students remained available to their family or others as opposed to a traditional class, where the students are primarily available to the instructor and fellow students. This supports Anderson's observation that for many students, the demands of profession, family, and community provide little extra time at any hour, and that the physical relocation that normally occurs during face-to-face classes provides a spatial separation from dayto-day pressures and commitments. "This separation can provide the face-to-face participant with increased amounts of available time" ([1], p. 133), a provocative caveat with which to conclude this discussion.

\section{CONCLUSION}

This study evaluated the student learning experiences with the instructional design components of an asynchronous course at a large urban university. The model developed for this course is considered appropriate for other faculty considering offering courses in an asynchronous mode. In considering the model, faculty should carefully assess the maturity and academic preparedness of their students as well as the subject matter of the course. Some adjustments and modifications will likely be necessary.

Lastly, it bears repeating that networking technology is changing rapidly. A few years ago, only a small percentage of academics in the United States and Western Europe, mostly in engineering and the sciences, were using computer networks for instruction on a regular basis. Today, the Internet and the Web are being used more frequently by educators at all levels, in all disciplines, and in all parts of the world. For those considering using networks as integral components of instruction as in asynchronous learning, on-going evaluation and study is highly recommended to determine if the techniques used meet the instructional needs of the students.

\section{ACKNOWLEDGEMENTS}

This paper was made possible with the assistance of the Alfred P. Sloan Foundation, Dr. Frank Mayadas, Program Officer; the Hunter College Distance Learning Award Program, Dr. David Caputo, President; and the City University Open Systems Center, Dr. Michael Ribaudo, University Dean and Colette Wagner, Director. The author is grateful for their support. 


\section{REFERENCES}

1. Schlosser, C.A., \& Anderson, M.L. Distance Education: Review of the Literature., DC: Association for Educational Communications and Technology, 1994.

2. Moore, M.G. \& Kearsley, G. Distance Education: A Systems View. Belmont, CA: Publishing, 1996.

3. Sherry, L. "Issues in Distance Learning." International Journal of Distance Education, 1 (4), 337365, 1996.

4. Ruberg, L. F., Taylor, C.D., \& Moore, D.M. "Student Participation and Interaction On-line: A Case Study of Two College Classes -- Freshman Writing and Plant Science Lab. "International Journal of Educational Telecommunications, 2 (1), 69-92, 1996.

5. Newman, D. "Cognitive and Technical Issues in the Design of Educational Computer Networking." In L.M. Harasim (Ed.), On-line Education: Perspectives on a New Environment (pp. 99-116). New York Praeger, 1990.

6. Lippman, M. Thinking in Education. Cambridge: Cambridge University Press, 1991.

7. Anderson, T. D. "The Virtual Conference: Extending Professional Education in Cyberspace. International Journal of Educational Telecommunications, 2(2/3), 121-135, 1996.

8. Sproull, L.S. \& Kiesler, S. Connections: New Ways of Working in the Networked Organization. Cambridge, MA: MIT, 1991.

9. Mackay, W.E. "Diversity in the Use of Electronic Mail: A Preliminary Inquiry." Transactions on Office Information Systems, 6(4), 380-397, 1989.

10. Varian, H. “The Information Economy.” Scientific American, 273(3), 200-202, 1995.

11. Trentin, G. "Internet: Does it Really Bring Added Value to Education". International Journal of Educational Telecommunications, 2(2/3), 97-106, 1996.

12. Stubbs, M. Language, Schools, and Classrooms. London: Methuen, 1976.

\section{About the Author}

Anthony G. Picciano has twenty-seven years of administrative and teaching experience specializing in the areas of education administration and educational technology. He has managed and been a director of several large-scale technology projects in the City University and State University of New York and has held several major administrative positions including dean at the College of Staten Island and vice president at Hunter College. He has served as a consultant for a variety of public and private organizations including the New York City Board of Education, the New York State Department of Education, the U.S Coast Guard, and CITICORP.

Dr. Picciano completed his $\mathrm{PhD}$ at Fordham University in 1985 and is currently a professor in the Education Administration and Supervision Program in the Department of Curriculum and Teaching at Hunter College. His teaching specializations include educational technology, organization theory, and research methods. He also has been a faculty fellow since 1994 at the City University Open Systems Laboratory, a facility dedicated to experimenting with advanced uses of instructional technology and to providing staff development programs for organizations including public schools, colleges, and private businesses. As part of his work with this Laboratory, he has made numerous presentations and conducts workshops and seminars for a variety of professional groups throughout the Northeast.

He has been involved with a number of major grants from the National Science Foundation, the U.S. Department of Education, IBM, and the Alfred P. Sloan Foundation. He is presently a project coordinator for the New York City Collaborative for Excellence in Teacher Preparation, a NSF-funded 
program designed to improve the teaching of science, mathematics, and technology in New York City schools.

His major research activity during the past five years has been in designing multimedia teaching and learning models. He has collaborated with The American Social History Project and Center for Media and Learning at CUNY on a number of projects dealing with subjects such as Irish immigration in the 1850 s, women's rights and labor issues at the turn of the century, and school integration in the 1950s.

One of these programs, The Five Points: A Multimedia Experience in Social History, was selected to be part of a New Learning Technologies Exhibit, held in San Diego in 1992. His present research interests are centered on distance learning technologies including asynchronous learning using Internet tools and media distribution systems.

Dr. Picciano has written a number of articles for professional journals and publications such as the Journal of Educational Multimedia and Hypermedia, Computers in the Schools, The Urban Review, Equity and Choice, and EDUCOM Review. His most recent book, Educational Leadership and Planning for Technology (1998, Simon \& Schuster) is a revision of his previous work, Computers in the Schools: A Guide to Planning and Administration (1994, Macmillan Publishing). 